\title{
2 | Science and citizenship in a global context
}

\author{
MELISSA LEACH AND IAN SCOONES
}

\section{Introduction}

Shifting science-society relationships are highly relevant both to contemporary practices of citizenship and their expression, and to questions concerning the dynamics of 'participation'. Just as political and economic changes are altering the contexts, arenas and ways in which people perceive and act on citizenship rights, so too are scientific and technological changes and the new risks and opportunities they present. Scientific and technological issues present particular challenges and opportunities for participation: on the one hand they are associated with claims to highly specialized, professionalized knowledge and expertise that may serve to exclude, yet on the other hand recent scientific controversies have also created new demands and opportunities for concerted citizen engagement in decision-making. At least in some contexts there is seen to be a new mood of public cynicism and critique of 'expert' institutions and their knowledges, and demands for new sorts of dialogue and public empowerment in the scientific realm.

Today these issues are reflected perhaps most clearly in the extensive academic, policy and media debates that explore contemporary relations between risk, science and society. In this chapter, we outline approaches that are helpful in exploring these issues in a globally comparative frame. The justification for this approach is twofold. First, these issues have to date been explored through distinct traditions of work associated with science and technology studies (STS), focusing predominantly on 'Northern' contexts, and development studies (DS), focusing predominantly on the global 'South'. ${ }^{1}$ This suggests a need both to explore the crosscontext 'translatability' of theories and debates and the possibilities of cross-learning between them. Second, a comparative approach allows an exploration of how citizenship and knowledge claims are emerging around different issues - from biotechnologies and road development to biodiversity and health technologies, for instance - in different settings, according to particular histories and contemporary dynamics in the relationships between science, state, international political economy and society.

In this chapter, we provide a review of some of the dominant lines of work in STS and DS that reflect on the relationships between science and 
citizenship. First, we consider major emphases in how each has conceived of the relationships between experts and lay knowledges, revealing some important contrasts in their approaches. We then go on to examine how different notions of citizenship have been incorporated into these debates, whether explicitly or implicitly. Through this discussion, we also address how diverse strands in the theoretical literature on citizenship (and the theories of democracy that link to these) $)^{2}$ provide different lenses for thinking about science, knowledge and the engagement between different perspectives. As we show, approaches to participation and deliberation, now central to thinking and action in a scientific context in both North and South, are underlain by particular concepts of the citizen, which variously enable and constrain their transformative potential. Today, these processes take place in a globalized context, and in a third section we reflect on how this context forces us to redefine further the relationships between science and citizenship. We show in this context why it is necessary to go beyond static, universalized and essentialized notions of citizenship and a singular notion of the state, to embrace a more fluid, decentred and experiencebased notion of both citizenship and expertise, but without losing sight of the historical, political and institutional structures that shape often highly contrasting forms of engagement.

\section{Perspectives on knowledge and expertise}

In order to explore these issues, we begin by considering the different analytical traditions for approaching knowledge and expertise relationships in STS and DS. While STS has relatively recently come to an interest in lay knowledge and experience-based expertise, DS by contrast draws on a much longer tradition of work examining local knowledge and practices and their conceptual and social underpinnings.

A recent review by Collins and Evans (2002) identifies two main waves in science studies to date. The first aimed at understanding, explaining and reinforcing the success of science, without questioning its basis. Science was held to be authoritative, objective and universal, and an unquestionable basis for expert-led decisions. Despite critiques from the early 1970 s by academics, this perspective continued to dominate in many policy contexts. Thus perceived crises of legitimacy in science among publics were deemed to be the result of public misunderstanding of science, a 'deficit' in public knowledge that should be filled through science education.

A second wave of science studies, however, focused on challenging the assumptions and practices of science. In a variety of works sharing a social constructivist approach (e.g., Barnes et al. 1996; Haraway 1991; Knorr-Cetina 1981), science - its framing of questions, experimental meth- 
ods, styles of investigation, modes of reaching closure, treatments of risk and uncertainty - was reconceptualized as a social and political activity. A prominent line of work focused on the details of 'laboratory life' (e.g., Latour 1987; Latour and Woolgar 1979) and examined the sets of practices that came to constitute science, and the ways these acquired authority in particular settings (Knorr-Cetina 1999; Pickering 1992). By emphasizing the way in which scientific knowledge was like other forms of knowledge, this work challenged the distinctions made between scientific experts and non-experts. Yet in this work the emphasis was on demystifying the practices of science, and parallel research attention was not applied to other knowledges in the public realm.

Nevertheless, an important strand of social science work did argue that public understandings of science were more sophisticated and nuanced than they had been given credit for, and that these understandings focused not just on the content and methods of science, but also on forms of its institutional embedding, patronage and control (Irwin and Wynne 1996; Wynne 1992). It also explored cases where laypeople had explicitly engaged with and contested science and its advice by conducting their own research and experiments (for instance, in 'popular epidemiology' concerning issues of toxic waste pollution; Brown and Mikkelsen 1990). Drawing attention to what has come to be labelled 'citizen science', this work demonstrated how publics now engage critically with the scientific perspectives of expert institutions, either through funding or orchestrating their own scientific investigations, or through lobbying to transform research questions (e.g., Fischer 2000; Irwin 1995).

Debates about citizenship and science in European settings have also been strongly influenced by Ulrich Beck's 'risk society' thesis and its subsequent elaborations (e.g., Beck 1992, 1995). Beck and others have been arguing that contemporary public critiques of scientific expertise are symptomatic of a broader, more fundamental set of social transformations, requiring new forms of sociological theorizing. The risk society thesis suggests that publics are increasingly concerned with risks that are no longer 'external', but continually thrown up by systems of industrial technology and its governance themselves. The scientific and bureaucratic apparatus charged with knowing and managing risk continues to operate according to ideas of predictability, so there is a mismatch between the character of hazards and what Beck terms 'relations of definition': the legal, epistemological and cultural power matrix in which discussions of science and technology are conducted (Beck 2000: 224). In the process, society has become 'reflexive', compelled by this mismatch to question its foundational principles (including ideas of scientific rationality) in an 